\title{
Mediumship accuracy: a quantitative and qualitative study with a triple-blind protocol
}

\author{
Patrizio Tressoldi ${ }^{\mathrm{a}, \mathrm{b} 1}$, Laura Liberale ${ }^{\mathrm{a}, \mathrm{d}}$, Fernando Sinesio ${ }^{\mathrm{a}}$, Valdimiro Bubba ${ }^{\mathrm{c}}$, Luciano \\ Pederzolic $^{\mathrm{c}}$, and Ines Testoni ${ }^{\mathrm{d}}$ \\ a'GRIM: Gruppo di Ricerca Italiano sulla Medianità \\ bStudium Patavinum, Science of Consciousness Research Group, Università di Padova, Italy \\ EvanLab, Firenze, Italy \\ dEnd of Life, FISSPA, Università di Padova, Italy
}

\section{[in press EXPLORE: The Journal of Science \& Healing]}

\begin{abstract}
Aims: assess if mediums could give accurate information about the deceased in a triple-blind protocol and to investigate the source of information using a quantitative and qualitative analysis.

Methods: nine mediums produced thirty-eight readings related to thirty-eight deceased individuals chosen by thirty-six sitters using a triple-blind protocol with no direct interaction with the sitters themselves.

In this protocol, the medium was provided with only the deceased's name by the interviewer, the latter having no further knowledge about the deceased. In every session, the medium was asked to provide information about two deceased persons of the same gender. This information, excluding generic details, was entered into two anonymous lists.

The information of these two readings was sent to the research assistant charged with maintaining contact with the sitters. Each sitter was asked to assign a value to every piece of information listed using a four- point Likert scale from 'totally wrong' to 'totally correct', and to provide a global score for each reading.

Results: $65.8 \%$ of the intended readings were correctly identified with respect to the chance of $50 \%$. Furthermore, intended readings had on average $29.5 \%$ more correct information than the control ones.

Qualitative data indicate that mediums attain information both passively and actively, that is as if they retrieved information without or directly interacting with the deceased.

Conclusions: this study provides further evidence that some mediums are able to obtain accurate information about deceased people knowing only the deceased's name and with no interaction with sitters; it also supports the hypothesis that, in some cases, the sources of the information are the deceased themselves.
\end{abstract}

Keywords: mediumship; triple-blind protocol; quantitative results; qualitative results; survival hypothesis

\footnotetext{
${ }^{1}$ Corresponding author: Patrizio Tressoldi; email: patrizio.tressoldi@unipd.it
} 


\section{Introduction}

Religions and many cultures of all ages and in every place have regulated the relationship with the dead through rituals that could be officiated and managed only by ministers and using very strict rules (Vail et al. 2019; Hodge, 2011). Despite this, the postmodern age has challenged not only the theoretical apparatuses based on religions, but also the moral habits and social rituals based on the religious explanation of the world (Caputo, 2007; Solomon et al. 2017; Testoni et al. 2015; Testoni et al. 2016).

Indeed, as widely discussed by Klass et al. (1996), mourners maintain continuing bonds for a long time with their deceased. This finding has gained widespread interest in the field of bereavement studies because continuing bonds have been shown to help mourners reconstruct the fundamental meanings of life and thus overcome the suffering of grief (Neimeyer et al, 2006; Neimeyer et al. 2014). However, continuing bonds are very often manifested as a realistic search for the deceased and not only as a readjustment of the relationship with the deceased. As a consequence, mourners often turn to mediums, believing that mediums can let them have a contact with the dead. Therefore, it is of interest to investigate the reliability of the mediums before considering whether the relationship with them can bring benefit or harm to mourners.

Interest in mediumship originated in antiquity and began to be scientifically investigated in the late 19th century. The modern scientific study of this topic, using enhanced methodological control of the source of information, is relatively recent (Beischel, 2018). Amongst the main aspects of this phenomenon, the most important are accuracy of the information given by mediums and its origin.

Consultation with a medium typically involves the presence of an inquirer -henceforth defined as a 'sitter'- who wants information about a deceased person through interaction with the medium. Obviously in these circumstances, the source of information could be from the inquirers themselves, who could either consciously or unconsciously give it to the medium through what is called 'cold reading' (Roe and Roxburgh, 2013) - that is to say, the transmission of verbal and nonverbal information which can confirm or deny the details given by the medium.

In order to eliminate this potential source of information, modern research protocols have been established to ensure that there is neither visual nor auditory communication between the sitter and medium and with other human or artificial sources of information related to the deceased person.

Regarding the assessment of the accuracy of statements by the medium, in order to prevent the sitters distorting them due to confirmatory bias - that is, the tendency to accept particular information as correct even if it is wrong simply because the sitter has a strong need for proof that his/her loved one is still alive, albeit in non-physical form, the modern research protocols require giving the sitter at least two anonymous readings to evaluate.

Sarraf, Woodley of Menie, \& Tressoldi (2020) meta-analyzed all experiments performed between 2001 and 2019 which used one or more levels of blindness, that is, protection from the possibility of the sitter giving information about the deceased and mistakenly evaluating the received information. Overall, the observed average accuracy from the 18 experiments included in the meta-analysis, was between $6 \%$ and $14 \%$ more than what is attributable to chance and was higher in mediums who had obtained a preliminary certification of their abilities.

In summary, despite eliminating the possibility of communication between sitter and medium and distortions the evaluation of received information (confirmatory bias), some mediums were able to produce correct information about the deceased people requested by sitters.

This study aimed to assess if mediums could give accurate information about the deceased in a triple-blind protocol and to investigate the source of information using a quantitative and qualitative analysis. The importance of qualitative analyses is described very well in a work by Beischel, Mosher and Bocuzzi (2017). Through this type of analysis, it is possible to obtain a description of the experience of mediumship by mediums themselves. It gives, for example, a description of the various stages of connection with the deceased, the sensory modality of received 
information, and the differences between readings regarding the deceased and those regarding living people.

\section{Ethics Board Review of the Study Protocol}

\section{Methods}

This study has been approved by the Ethical Committee of Psychological Research of Padova University (Protocol no. 3670). Both mediums and sitters were requested to read and orally confirm the protocol to provide informed consent.

\section{Participants}

Of the nine mediums who participated in the study, some were contacted directly by the authors, while the others volunteered because it gave them the chance to obtain certification for the attainment of particular accuracy criteria.

All of them were female, with an average age of 42 years, ranging from 28 to 68. Most of them were professional mediums. It is important to consider that this sample cannot be considered representative of the Italian mediums, given the lack of information about this population.

The 36 sitters were contacted by the authors from people who had a serious interest in having a reading related to a deceased relative or friend, independent of cause of death or length of time since the death.

\section{Procedure}

The experimental procedure was adapted from that presented by Beischel (2007). The sitters who were interested in having a free consultation for a deceased loved one were asked to provide his/her first name, the age of death and the time since the passing. This information was kept by one of the co-authors, who will be called 'research assistant B' (raB).

The mediums were contacted for the consultation by another co-author, who will be called 'research assistant A' (raA). On the day of the consultation, raA contacted the medium via either Skype or WhatsApp and gave her only the deceased's name (without the surname) as given by raB. Italian first names did not convey any information about age and ethnicity.

The medium was required to provide oral information relative to the deceased, which was to include a physical description of the person during life and any other information pertinent to the deceased's identification by the sitter, as well as anything the deceased wished to communicate to the sitter. At the conclusion of the reading, raA electronically recorded each information into a column, excluding general sentiments, for example "I love you" or "Don't worry about me", “I'm well", etc, and sent them to raB.

In a session, each medium was always asked to contribute two readings of pairs of deceased individuals of the same gender, male or female being the only common characteristic. In the traditional procedure described by Beischel (2007) and applied by other researchers (e.g. Beischel, Boccuzzi, Biuso, \& Rock, 2015), in order to simplify the comparison between readings, the two deceased persons must have different causes of death, personality traits and hobbies.

If requested by the medium, it was also possible to complete the reading over the phone, in which case the sitter was only allowed to listen to the medium, but not to interact in any way with her.

Once $\mathrm{raB}$ received the two reading outcomes from raA, the information was written on two different lists for evaluation of each of them and for global evaluation (see the example in the Appendix). Afterwards, both readings were sent anonymously to the requesting sitters by raB, providing assistance to them if needed for the evaluation procedure.

When the two sitters sent the evaluated readings to $\mathrm{raB}$, he sent them to another co-author, who will be called 'research assistant C' ( $\mathrm{raC}$ ), also blind to the identity of the deceased persons, for checking the sitters' responses and, if necessary, requesting clarification from the sitters regarding the choice of values assigned in the evaluation. 
After checking them, raC sent the two readings to raB, whose task was to quantitatively and qualitatively evaluate the information judged as correct or incorrect.

In summary, the research protocol involved three levels of blindness for the deceased's identity: the mediums, the raA and the sitters.

\section{Evaluation of readings information}

Each element of information from the two reading lists evaluated by the sitters was given the following scores: "perfectly correct" : 1 ; somewhat correct": 0.5 ; somewhat wrong": -0.5 : "clearly wrong" :-1.

Subsequently, excluding information marked as "I don't have information for evaluation", the percentages of this information were calculated (see database available at https://doi.org/10.6084/m9.figshare.13311710.v1 ). These differences could range from $-100 \%$ if all wrong, to $100 \%$ if all correct.

As well as evaluating each piece of information from the pair of readings, the sitter was also asked to give an overall evaluation for each of them, using a scale from 0 (the information is totally wrong) to 6 (excellent: effectively free of errors and contains compelling evidence of authentic communication), identical to the scale used in Beischel, (2007). When both outcomes were given identical scores, the sitter was neverthless asked to choose one as the better.

From a qualitative point of view, each piece of information provided by the medium was classified as either "direct interaction with the deceased" or "without apparent interaction". The first category included all information in which the medium reported direct interaction with the deceased, for example, "He is showing me...", or "She tells me...". The second category included all other information, e.g., "I see that...", "I feel that...", etc.

\section{Results}

\section{Characteristics of the deceased chosen by the sitters}

The age at death of the deceased people was between 14 and 97 years, with an average of 58 years and standard deviation $=21.6$.

The elapsed time since the deaths was from 0.5 to 45 years, with an average of 10.38 years and standard deviation $=10.37$.

\section{Number of readings contributed by the mediums}

Among the nine mediums, three of them contributed with only two readings, three did with four readings, two had six readings and the last one contributed eight readings. These differences were due to the availability of the mediums.

\section{Quantitative Analyses}

Only one medium chose the option of 'silent sitter' for a pair of readings. All other mediums opted for 'absent sitter'. In any case, even with a "silent sitter", the triple-blind conditions were maintained because both the medium and the raA were kept blind about the identity of the sitters and the sitters were kept blind about which reading was the intended one for their deceased.

Of 38 readings, collected from April to November 2020, the sitters correctly identified their own deceased person $65.8 \%$ of the time (25/38). From a statistical point of view, this result corresponds to a value of $p=0.036$ (one-tailed) to the binomial test.

The average score and standard deviation of overall scores assigned to the readings are:

-Intended: Mean $=3.36 ; \mathrm{SD}=1.47$;

-Control: Mean $=1.77 ; \mathrm{SD}=1.3$.

The unpaired mean difference between the overall scores assigned to the correct and incorrect readings is $1.59 ; 95 \% \mathrm{CI}=0.609,2.41$ (confidence intervals are bias-corrected and accelerated, estimated with 5000 bootstrap samples). See also Figure 1. 
The probability value of the two-sided permutation $t$-test (Ho et al. 2019) is $p=0.001$.

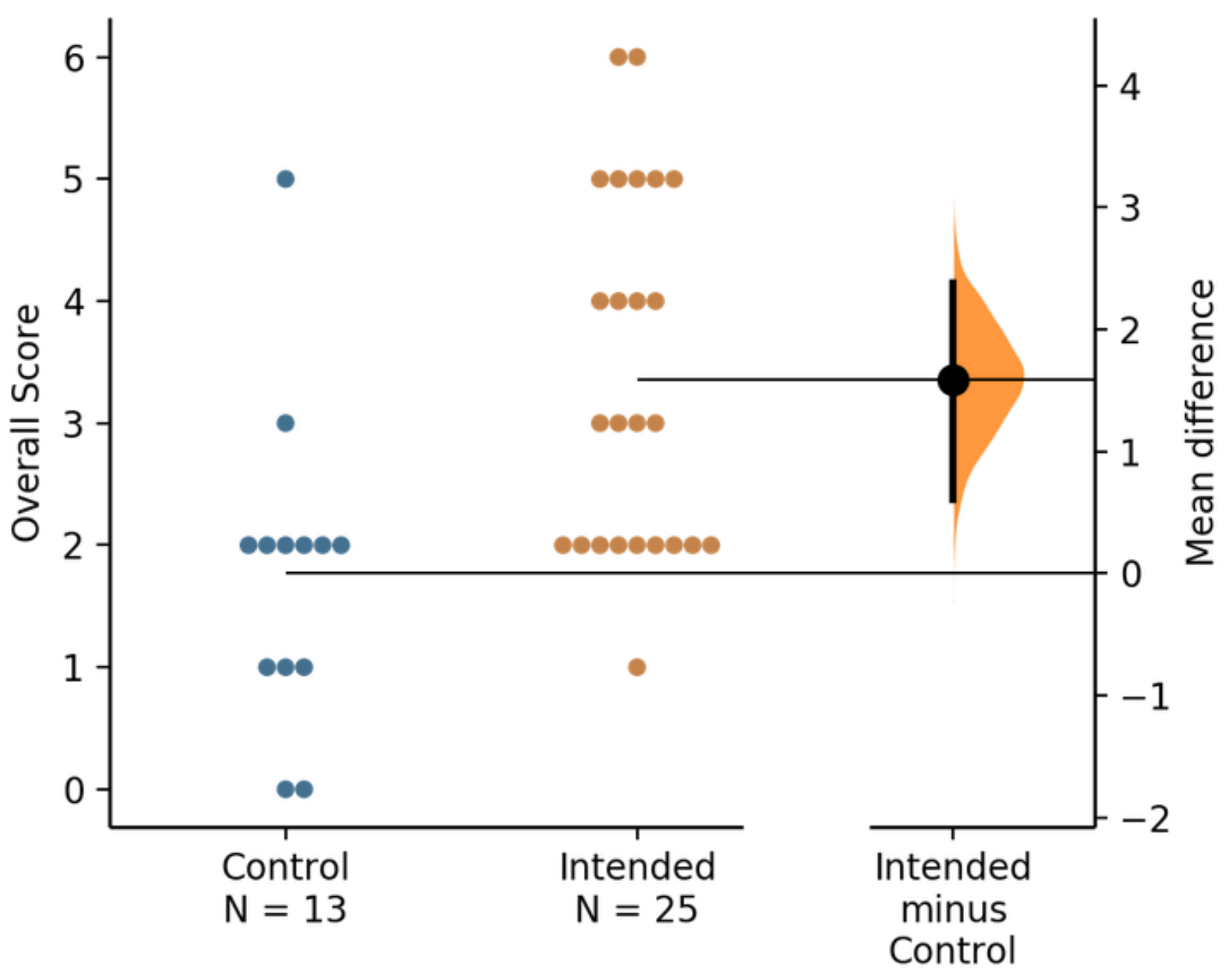

Figure 1: Gardner-Altman estimation plot of the overall scores assigned to the intended and control readings.

\section{Comment}

Bearing in mind that the overall evaluation scale of the outcomes is 0 to 6 , the intended readings correctly identified had an average score of 3.36 , which on average is 1.59 points higher than the control ones.

The difference between the percentages of correct and incorrect information related to intended readings was: Mean $=0.078 ; \mathrm{SD}=0.37$. For the control reading: Mean $=-0.216 ; \mathrm{SD}=$ 0.41 .

The unpaired mean difference between intended and control readings is 0.295 [95\% CI $=$ $0.0218,0.536]$. See also Figure 2 . The probability value of the two-sided permutation t-test (Ho et al. 2019) is $p=0.0268$. 


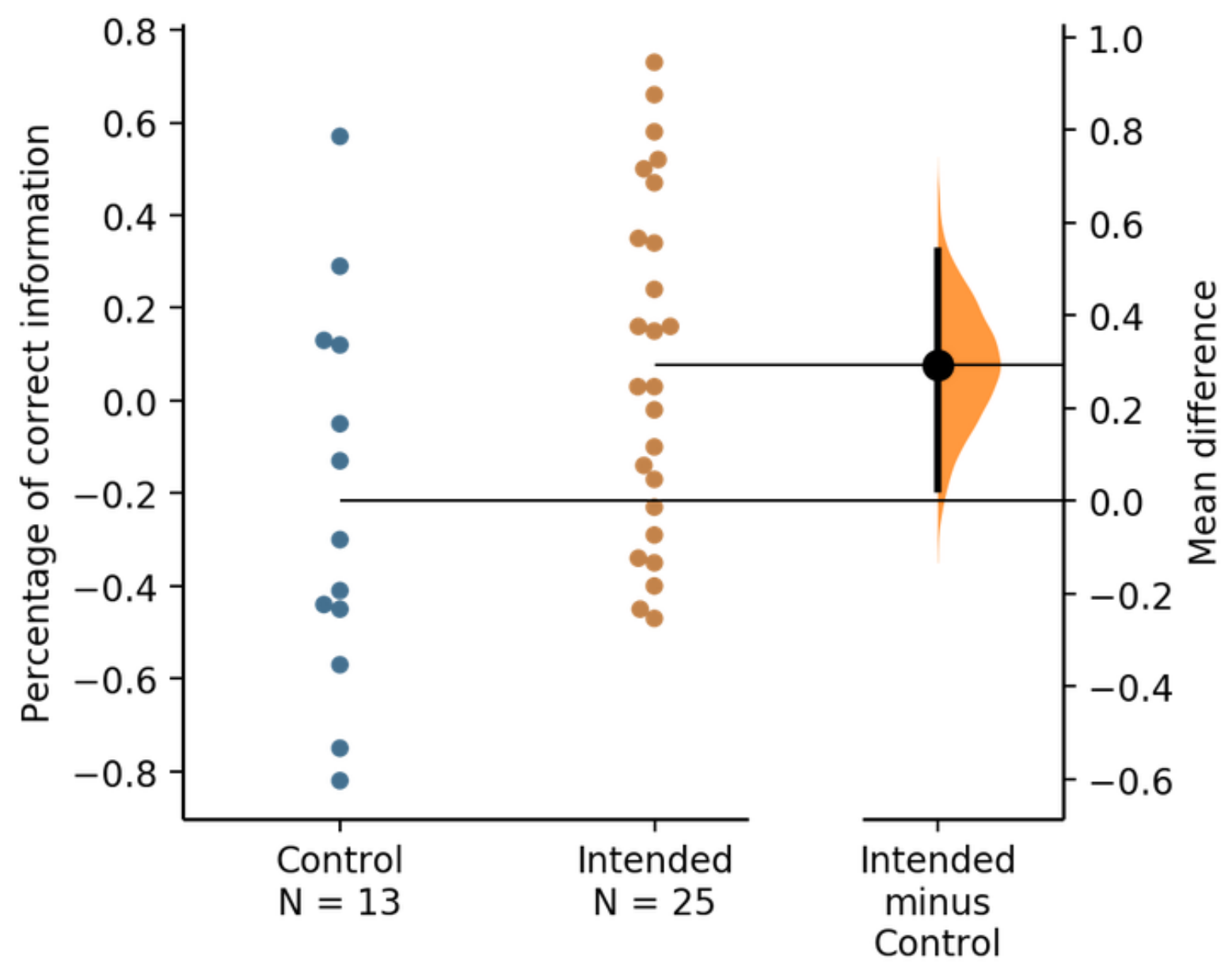

Figure 2: Gardner-Altman estimation plot of the percentage of correct information of the intended and control readings.

\section{Comment}

With respect to the control readings, those intended which were correctly identified showed on average $29.5 \%$ more correct information compared to the control ones.

As expected, the correlation between the overall scores and the percentages of correct information is positive, with $r=.82$; 95\% CIs: $.72-.93$ estimated with a bootstrap procedure with 1000 samples.

\section{Qualitative Analyses}

The amount of information indicating a direct interaction with the deceased was always less than the information in the "without apparent interaction" category (i.e., without any clear interaction with the deceased) for all mediums. Nonetheless this relationship was shown to be quite variable, ranging from a minimum of $1 \%$ to a maximum of $43 \%$ (see Table 1 ).

Table 1: Ratio between information classified as "direct interaction with the deceased" with that classified as "without apparent interaction" in decreasing order.

\begin{tabular}{c|c}
\hline Medium & Ratio \\
\hline So & .43 \\
\hline Mar & .28 \\
\hline
\end{tabular}




\begin{tabular}{c|c}
\hline Su & .26 \\
\hline Sl & .26 \\
\hline $\mathrm{L}$ & .17 \\
\hline $\mathrm{Ma}$ & .16 \\
\hline $\mathrm{I}$ & .14 \\
\hline $\mathrm{V}$ & .14 \\
\hline $\mathrm{E}$ & .10 \\
\hline
\end{tabular}

\section{Comment}

Some mediums showed a consistently high ratio between these two categories of information, suggesting that it could be due to their individual differences in how the information is acquired. The correlation between these values and the average overall and accuracy scores, yielded very low and statistically non significant Spearman rho values: .22 and -.017 respectively.

\section{Discussion}

This study confirms that some mediums are able to correctly gather information about deceased people from a name only, without directly interacting with the sitter or anyone else familiar with the deceased person.

It is worth remembering that the protocol used here included conditions which made evaluations by sitters more difficult than in previous studies: the two readings to be assessed had only the gender of the deceased person in common, while all other characteristics were not required to be different.

Furthermore, the implemented accuracy criterion took into consideration the percentage of correct information as well as the incorrect one.

So, if we rule out the possibility that this information can be obtained by using conventional mean, where is it collected from?

In the literature there are two opposing hypotheses about this, one defined as Living Agent PSI (LAP or SuperESP) and one referred to as Survival hypothesis (Sudduth, 2009; Braude, 2014). According to the LAP hypothesis, mediums can obtain information by mentally connecting (telepathically) with sitters or with those who knew well the deceased person.

On the other hand, the Survival hypothesis states that all that was experienced in physical life can be stored somewhere, such as the Akasha (Laszlo, 2014), a sort of passive memory of individual experiences, together with all other experiences of all beings who have lived on Earth or obtained directly from what survive of a person after his/her physical death.

Our data indicate that for the LAP theory to be correct, the telepathic abilities required would need to be so advanced that no study has ever confirmed them. All studies on telepathic abilities have shown that it is possible only to send and receive images, short video clips or other types of visual or auditory information using this method, but always via mental interaction with a specific individual partner (e.g. Storm and Tressoldi, 2020).

The protocol used here prevented the medium from knowing anything about the sitters' information about their deceased persons. Furthermore, the probability of identifying telepathically the specifically requested deceased person from only a name, even if theoretically possible, but without any evidence with a task similar to that one used in this study, to our knowledge at least, made this hypothesis almost impossible.

The qualitative data collected from this study suggest instead that some mediums can obtain some of their information through a real and proper interaction with the deceased. This would indicate that an accurate reading requires the input from three protagonists: the sitter, the medium, and the deceased.

The sitters' task is to ask for information about a deceased person to whom they were close and with whom they most likely had a strong emotional bond. The medium's task is to contact the deceased individual who was requested by the sitter, avoiding any information from other deceased 
entities. Finally, what survives of a deceased person, e.g., his/her consciousness, must presumably maintain a desire to allow contact with the medium to provide information to the sitter.

As a further support to the hypothesis of a real interaction with the deceased, we highlight two particular episodes. A sitter evaluated the reading related to the control deceased person, Maria Angela, giving it an overall value of 5, which corresponds to "good: contains very few incorrect points", but attributing it to her deceased, Consuela. We wondered how such an error was possible after having carefully checked and ruled out the possibility of mixed-up results: can we speculate that, even though the medium was asked to contact Maria Angela, the deceased who actually appeared was Consuela?. In any case we scored this evaluation as an error.

The second episode was due to an error by the raB, who sent the wrong name of a deceased person - 'Romualdo' instead of 'Rolando' - to the raA, who obviously forwarded it to the medium. Despite this error, the reading was identified as correct by the sitter, giving it an overall score of 5 and a very high difference between correct and incorrect information.

Obviously more proof is required regarding the possibility that some mediums can interact with the deceased persons, but we believe that qualitative analyses of collected information can be a useful means for this objective.

As methodological suggestions for future studies on this topic we suggest the followings: -weight the information according to their chance probability. For example: "He was tall" has a higher chance probability than "He died when he was 49 years-old";

-if it is assumed that information derives from exceptional telepathic skills, they must be tested directly and not only assumed as postulated for example by the LAP hypothesis;

- to keep the task difficulty similar for the mediums, it would be better to use a fixed sample of deceased persons because it is not taken for granted that their information is equally findable. A fixed sample of questions for the deceased persons should also be used. 


\section{Acknowledgments}

We thank the anonymous reviewers and the chief editor for their suggestions and constructive criticisms and all participating mediums for their interest in the scientific investigation of their skills. We also thank Cinzia Evangelista and the Proof-Readings-Service for English revision. 


\section{References}

Beischel, J. (2007). Contemporary Methods used in laboratory-based mediumship research. Journal of Parapsychology, 71, 37-68.

Beischel, J. (2018). Mental Mediumship Research | Psi Encyclopedia. Retrieved November 19, 2020, from https://psi-encyclopedia.spr.ac.uk/articles/mental-mediumship-research

Beischel, J., Boccuzzi, M., Biuso, M., \& Rock, A. J. (2015). Anomalous information reception byresearch mediums under blinded conditions II: replication and extension. EXPLORE: The Journal of Science and Healing, 11(2), 136-142. https://doi.org/10.1016/J.EXPLORE.2015.01.001

Beischel, J., Mosher, C. \& Boccuzzi, M.(2017). Quantitative and qualitative analyses of Mediumistic and Psychic Experiences. Threshold: Journal of Interdisciplinary Consciousness Studies, 1, 2, 51-91.

Braude, S. E. (2014).The possibility of mediumship: Philosophical considerations. In The Survival Hypothesis: Essays on Mediumship edited by A. J. Rock, Jefferson, NC: McFarland, pp. 2139.

Caputo, J. D. (2007). Atheism, a/theology, and the postmodern condition. In M. Martin (Ed.), The Cambridge companion to atheism. (pp. 267-282). Cambridge University Press. https://doi.org/10.1017/CCOL0521842700.017

Ho, J., Tumkaya, T., Aryal, S., Choi, H., \& Claridge-Chang, A. (2019). Moving beyond P values: Everyday data analysis with estimation plots. Nature Methods, 1548-7105. https://doi.org/10.1038/s41592-019-0470-3

Hodge, K. M. (2011). On Imagining the Afterlife. Journal of Cognition and Culture, 11(3-4), 367389. doi:10.1163/156853711X591305

Klass, D., Silverman, P. R., \& Nickman, S. L. (Eds.). (1996). Continuing bonds: New understandings of grief. Washington, DC: Taylor \& Francis.

Laszlo, E. (2014). The Self-Actualizing Cosmos: The Akasha Revolution in Science and Human ... Ervin Laszlo - Google Books. Simon and Schuster.

Neimeyer, R. A., Baldwin, S. A., \& Gillies, J. (2006). Continuing bonds and reconstructing meaning: Mitigating complications in bereavement. Death Studies, 30, 715-738.

Neimeyer, R.A., Klass, D., \& Dennis, M.R. (2014). A social constructionist account of grief: Loss and the narration of meaning. Death Studies, 38, 485-498.

Rock, A. J. \& Storm, L. C. (2015). Testing telepathy in the medium/proxy-sitter dyad: A protocol focusing on the source-of-psi problem. Journal of Scientific Exploration, 29, 565-584.

Roe, C.A., \& Roxburgh, E. (2013). An overview of cold reading strategies. In C. Moreman (Ed.) The Spiritualist Movement: Speaking with the Dead in America and around the World: Volume 2, Belief, Practice, and Evidence for Life after Death. (pp. 177-203). Santa Barbara, CA: Praeger. ISBN: 978-0-3133-9947-3

Sarraf, M., Woodley of Menie, M. A., \& Tressoldi, P. (2020). Anomalous information reception by mediums: A meta-analysis of the scientific evidence. Explore.

https://doi.org/10.1016/j.explore.2020.04.002 
Solomon, S., Testoni, I., \& Bianco, S. (2017). Clash of civilizations? Terror Management Theory and the role of the ontological representations of death in contemporary global crisis. TPM Testing Psychometric Methodology in Applied Psychology, 24(3), 379-398. doi:10.4473/TPM24.3.5

Storm, L., \& Tressoldi, P. (2020). Meta-Analysis of Free-Response Studies 2009-2018: Assessing the Noise-Reduction Model Ten Years On. PsyArxiv, https://doi.org/10.31234/osf.io/3d7at

Sudduth M. (2009). Super-psi and the survivalist interpretation of mediumship. Journal of Scientific Exploration, 23:167-193.

Testoni, I., Parise, G., Visintin, E.P., Zamperini, A., \& Ronconi, L. (2016). Literary plastination: From body's objectification to the ontological representation of death, differences between sickliterature and tales by amateur writers. TPM - Testing, Psychometrics, Methodology in Applied Psychology, 23(2), 247-263. doi:10.4473/TPM23.2.8

Testoni, I., Ancona, D., \& Ronconi, L. (2015). The Ontological Representation of Death. OMEGAJournal of Death and Dying, 71(1), 60-81. doi:10.1177/0030222814568289

Vail, K. E., III, Soenke, M., \& Waggoner, B. (2019). Terror management theory and religious belief. In C. Routledge \& M. Vess (Eds.), Handbook of terror management theory. (pp. 259-285). Elsevier Academic Press. https://doi.org/10.1016/B978-0-12-811844-3.00011-1 


\section{Appendix}

Excerpt of the reading format

\section{Instructions}

For each of the following information indicate with an ' $x$ ' what you consider to be referring to [name of deceased], for whom you requested a reading.

For those which are sufficiently or perfectly correct please also indicate if the information is new (previously unknown), but which has been verified from reading these lists.

Reading 1

\begin{tabular}{|l|l|l|l|l|}
\hline $\begin{array}{c}\text { Not enough } \\
\text { information for } \\
\text { an assessment }\end{array}$ & Clearly wrong & $\begin{array}{c}\text { Somewhat } \\
\text { wrong (please } \\
\text { explain) }\end{array}$ & $\begin{array}{c}\text { Somewhat } \\
\text { correct (please } \\
\text { explain) }\end{array}$ & $\begin{array}{c}\text { Perfectly } \\
\text { correct }\end{array}$ \\
\hline Info 1 & & & & \\
\hline Info $2 \ldots$ & & & \\
\hline
\end{tabular}

Reading 2

\begin{tabular}{|l|l|l|l|l|}
\hline $\begin{array}{c}\text { Not enough } \\
\text { information for } \\
\text { an assessment }\end{array}$ & Clearly wrong & $\begin{array}{c}\text { Somewhat } \\
\text { wrong (please } \\
\text { explain) }\end{array}$ & $\begin{array}{c}\text { Somewhat } \\
\text { correct (please } \\
\text { explain) }\end{array}$ & $\begin{array}{c}\text { Perfectly } \\
\text { correct }\end{array}$ \\
\hline Info 1 & & & \\
\hline Info $2 \ldots$ & & & \\
\hline
\end{tabular}

Now for both readings assign an overall value by choosing a score between 0 and 6 according to the following scale:

$6=$ The reading is excellent, it contains compelling evidence of authentic communication and effectively has no wrong information.

$5=$ The reading is good and contains very few incorrect points.

$4=$ The reading is good, but contains some incorrect information.

$3=$ The reading contains a mix of correct and wrong information, however it has enough correct information to indicate that there was indeed communication with the deceased.

$2=$ Some information was correct, but not enough to be certain of real communication with the deceased.

$1=$ The entire reading contains very little correct information.

$0=$ The reading contains absolutely incorrect information.

\begin{tabular}{|l|l|}
\hline & Overall score \\
\hline Reading 1 & \\
\hline Reading 2 & \\
\hline
\end{tabular}

